\title{
COELHO NETO NA RUA DO OUVIDOR: EXPERIÊNCIA URBANA E MODERNIDADE NO ROMANCE BRASILEIRO DO FINAL DO SÉCULO XIX
}

\author{
Alessa Patricia Dias da Silva (UERJ) \\ Leonardo Mendes (UERJ) \\ leop@cruiser.com.br
}

A rua do Ouvidor surgiu em 1568 com o nome de Desvio do Mar. Em 1870, recebeu essa alcunha por abrigar o então ouvidor Francisco Berquó da Silveira, oficial de justiça da cidade. Em 1897, já na república, a rua passou a ser chamada de para Moreira César, mas o novo nome não pegou. A rua começou a ganhar importância com a vinda da família real para o Brasil, por conta da abertura dos portos, em 1808. Comerciantes desembarcavam da Europa e se instalavam naquela área. A rua se transformou na principal artéria do centro do Rio de Janeiro. E tudo que lá acontecia irradiava para o resto do país. Espaço de circulação por excelência, no qual as pessoas afluíam em busca de novas mercadorias e de posição social no jogo ver e ser visto, a rua criava laços sociais e construía um imaginário urbano que se instaurava na dicotomização entre o público e o privado, a casa e a rua (RODRIGUES, 2006).

No conto "Tempos de crise" (1873), Machado de Assis (1839-1908) diz que a rua do Ouvidor resumia o Rio de Janeiro, era o rosto da cidade fluminense - cenário do frenesi urbano, espaço da moda, da fofoca, do aconchego. João do Rio (1881-1921), no livro de crônicas A alma encantadora das ruas (1908), descreve desta forma a rua do Ouvidor: "Vede a rua do Ouvidor. É a fanfarronada em pessoa, exagerando, mentindo, tomando parte em tudo, mas desertando, correndo os taipais das montras a mais leve sombra de perigo. Esse beco inferno de pose, de vaidade, de inveja, tem a especialidade da bravata. E fatalmente oposicionista, criou o boato" (1997, p. 8).

A rua do Ouvidor era considerada o maior centro produtor e difusor de fofocas da cidade do Rio de Janeiro. Era uma rua bem estreita, "tinha apenas 6,7 metros de largura, e seu calçamento era péde-moleque, isto é, com pedras de contorno irregular" (TRIGO, 
2001, p. 27). A sua largura, ou falta dela, era o que permitia a disseminação de boatos e essa certa "sensação de intimidade". O bairro ao redor, com lojas, cafés, confeitarias e restaurantes era uma vitrine da Europa, sobretudo de Paris. Local do consumo e do encontro: "Era ali que se espalhavam os mexericos e que se tecia a pequena história da vida literária e artística do Rio de Janeiro" (MÉRIAN, 1988, p. 456). Vários movimentos literários e políticos nasceram nas confeitarias e cafés da Ouvidor. Além de Machado, Olavo Bilac (18651918), Rui Barbosa (1849-1923), Joaquim Manoel de Macedo (1820-1882), Coelho Neto, Paula Nei (1858-1897), Quintino Bocaiúva (1836-1912), e outras tantas personalidades podiam ser vistas circulando pela rua.

De acordo com Oliveira (2008), a rua do Ouvidor era o local aonde a burguesia ia para se cobrir de requinte na loja de nomes afrancesados. Desta forma, se configurava como o lugar por excelência do embate paradoxal existente entre a boemia e os burgueses. Local do capitalismo, do consumo desenfreado, mas ao mesmo tempo local de passagem da boemia, ou melhor, lugar da morada boêmia. A boemia era acolhida pela rua não somente pela flexibilidade dos padrões morais ali permitidos, mas, sobretudo, por não ter outro lugar aonde ir: "Escritores, jornalistas, pintores, atores e músicos, homens e mulheres, brasileiros e estrangeiros erravam durante o dia pelas redações dos jornais e livrarias, em tertúlias literárias pelos cafés e restaurantes próximos às do Ouvidor (...). Lá bebiam seu grogs geralmente a credito até que a noite surgisse" (OLIVEIRA, 2008, p. 51).

O boêmio, ao passear pela rua, que já se ergue com sinais de modernização, experimenta a flanerie urbana. Segundo João do Rio (1997), flanar é ser vagabundo e refletir, é ser basbaque e comentar, ter o vírus da observação ligado ao da vadiagem. O flâneur reconstrói a cidade e o seu olhar retrata a cena urbana. É no alarido da rua que o flâneur perambula e desenvolve a arte de ver. Os olhos do flâneur descortinam o cenário múltiplo das ruas. O olhar dos escritores, ao passearem pela cidade, registra o desenho da então Capital Federal. Eles assumem a condição de flâneur, debruçam-se sobre a cidade, voltam seus olhares para o espetáculo urbano. Desenvolvem a arte de ver, buscando uma nova percepção da cidade. A boemia vivia intensamente a flanerie urbana, tinha o gosto da observação. Os boêmios andavam pelas ruas pelo simples prazer de perambular, apre- 
endendo cada detalhe, buscando uma nova percepção da cidade. A rua configura-se, desta forma, como matéria-prima e fonte de inspiração.

Há uma relação forte entre os indivíduos, a sociedade e a rua. Eles interagem e se influenciam reciprocamente, são um contínuo, uma extensão uns dos outros. A rua é o espaço que cria a unanimidade, mas é também aquele da diversidade. A rua é o lugar nivelador das diferenças.

A rua é a civilização da estrada. Onde morre o grande caminho começa a rua, e, por isso, ela está para a grande cidade como a estrada está para o mundo. Em embrião, é o princípio, a causa dos pequenos agrupamentos de uma raça idêntica. Nas grandes cidades a rua passa a criar o seu tipo, a plasmar o moral dos seus habitantes, a inocular-lhes misteriosamente gostos, costumes, hábitos, modos, opiniões políticas (RIO, 1997, p. 14).

A rua é o acontecer da modernidade. Suas transformações dramatizam as mudanças que a sociedade e a cidade estavam vivendo. No espaço da rua eclodiam todos os tipos de relações humanas. Não se pode falar de rua, boemia e modernidade sem tocar no cerne da questão: a experiência urbana. A experiência urbana pode ser analisada na confecção dos romances A capital federal (1893) e A conquista (1899), de Coelho Neto, de duas formas distintas. Podemos assim dizer que temos nestes romances dois tipos de experiência urbana: uma construída dentro da diegese, tendo a rua do Ouvidor como espaço simbólico, como representação. E a outra extradiegética, que se relaciona com a vida da juventude boêmia, de que o jovem Coelho Neto participou. Vamos ao primeiro tipo.

Em A conquista, temos a reconstituição da vida literária dos fins do século XIX, livro do triunfo da geração boêmia. A narrativa nasce das andanças e encontros aleatórios pela cidade. Os boêmios em suas desventuras romanescas flanavam pelo Rio de Janeiro. Em um trecho do romance, o narrador ${ }^{2}$ faz um apêndice na descrição de

\footnotetext{
${ }^{2}$ Apesar de o romance ser autobiográfico e memorialista, não se devem confundir narrador e autor. Ainda que ocorra esta vinculação entre Coelho Netto e Anselmo, não podemos confundilos, uma vez que essa proximidade faz parte do simulacro que é a literatura. Segundo Leite (1985), essa proximidade pode nos dar a ilusão de que estamos diante de uma pessoa no expondo diretamente seus pensamentos, quando, na verdade, tanto o narrador como o leitor ao
} 
umas andanças realizadas por Anselmo e descreve a rua do Ouvidor, que neste trecho não se comporta como mera expectadoras ou coadjuvante, mas assume o papel de personagem.

Anselmo foi-se. A rua do Ouvidor, sem movimento, tinha o aspecto desolado de viela abandonada. As ruas do Rio de Janeiro, como as de Paris, segundo Balzac, têm qualidades e vícios humanos: há ruas estróinas e há ruas pacatas, ruas ativas e ruas negligentes, ruas devassas e ruas honestas, umas cujos nomes andam constantemente em notas policiais, outras que são citadas nas descrições elegantes (COELHO NETO, 1929, p. 57).

A rua do Ouvidor é trêfega. Durante o dia toda ela é vida e atividade, faceirice e garbo; é hílare e gárrula; aqui, picante; além ponderosa; sussurra um galanteio e logo emite uma opinião sisuda, discute os figurinos e comenta os atos políticos, analisa o soneto do dia e disseca o último volume filosófico. Sabe tudo - é repórter, é lanceuse, é corretora, é crítica, é revolucionária. Espalha a notícia, impõe o gosto, eleva o câmbio, consagra o poeta, depõe os governos, decide as questões à palavra ou a murro, à tapona ou a tiro e, à noite, fatigada e sonolenta, quando as outras mais se agitam, adormece. Ouve-se apenas o rumor constante dos prelos nas oficinas dos jornais. É a rua que digere a sua formidável alimentação diária para, no dia seguinte, pela manhã, espalhar pelo país inteiro a substância que compõe a nutrição do grande corpo, cada parte para o seu destino (p. 58).

Além de personagem, a rua é também uma projeção da sociedade. $\mathrm{O}$ romancista incorpora à rua as características de seus transeuntes. Lugar e metáfora, a cidade é a terceira margem, pois se nela instaura a possibilidade de outro lugar. Foge-se, pois, das dicotomias desgastadas, das estruturas binárias. É uma terceira via de significação, um lugar simbólico. Não se pode entender a construção romanesca enxergando a cidade apenas como cenário. Ela pode ser, ou melhor, é muito mais do que isso.

A rua do Ouvidor dentro do romance A conquista assume diversos papéis simbólicos. Ela é o lugar do medo, da incerteza, do luxo, da fome, da boemia. Ela é também o lugar do encontro por excelência; nela os boêmios teciam laços de amizade e irmandade. A amizade entre Anselmo (Coelho Neto) e Ruy Vaz (Aluisio Azevedo), personagens do romance, nasce na rua do Ouvidor: "Assim imaginava Anselmo a casa de Ruy Vaz, à qual se dirigia pela primeira vez. Conhecera o romancista na rua do Ouvidor, dias antes e ia vê-lo na

qual se dirige são seres ficcionais que se relacionam com os reais, através de convenções narrativas. 
intimidade do gabinete, nas sua vestes maneiras de trabalho" (p. 4). A rua também é o local das oportunidades, uma vez que vários jornais tinham sede na rua do Ouvidor. Os escritores que não conseguiam viver do trabalho literário recorriam a estes jornais na esperança de poder sobreviver de alguma forma da escrita. Eram jovens cultos e pobres, que, sem proteção social, são empurrados para o jornalismo, cuja expansão sem precedente se deveu, em parte, como ocorreu em Paris, à contribuição desses recém-chegados (BOURDIEU, 1996).

A imprensa foi, na época, uma grande aliada do movimento pela abolição. Mendes e Vieira (2009) afirmam que a vida boêmia não se baseava somente na galhofa e na algazarra da vida estudantil, a partir da qual dariam forma a seus versos e à sua prosa. Ser boêmio para eles significava também certa postura de ação e de pensamento. No caso desses jovens, tal impulso se materializava no engajamento profundo, no início da década de 80, com a causa abolicionista, Anselmo, protagonista de A conquista, "estreou na imprensa com um piedoso artigo sobre os velhos negros" (COELHO NETO, 1985, p. 163).

A rua do Ouvidor foi o grande palco da campanha abolicionista. O jornal Cidade do Rio, fundado por José do Patrocínio foi "o jornal que fez a parte mais aguda da campanha abolicionista" (BROCA, 1956, p. 12). Diante a proclamação da lei que libertava o país do jugo de anos escravidão, a multidão afluía eufórica pela rua.

Foi com violência inesperada de uma erupção vulcânica que irrompeu na Câmara um projeto de lei extinguindo a escravidão. Discutido com urgência fogosa dos propagandistas que reputavam a necessidade nacional, venceu impetuosamente a primeira represa, subindo ao Senado onde foi acolhido com simpatia quase unânime (COELHO NETO, 1985, p. 256).

$\mathrm{O}$ decreto foi assinado afluindo o povo à rua do Ouvidor, onde já aflavam bandeiras em triunfo, fazendo uma abóboda policrômica, como uma cena de lenda oriental (p. 257).

A rua estava apinhada, densa e fervilhando, e todos os olhos fitavam a tabuleta do jornal que fora o reduto da abolição. O dia, muito azul, concorria para a imponência da festa e o povo, frenético agitava-se com um sussurro perene. As bandeiras balouçavam-se, estouravam foguetes, vivas estrugiam (p. 264).

A boemia passa grande parte do romance descendo e subindo a rua do Ouvidor. Esse era o local do êxodo boêmio. Essas andanças 
interferem de maneira decisiva na construção romanesca. A organização dos capítulos, na narrativa, é circunstancial, um dobrar aleatório de esquinas, como um andarilho que atravessa a cidade e encontra os amigos e bebe, conversa, conta anedotas.

Em A capital federal, o herói, Anselmo, vem de Minas visitar o Rio de Janeiro. Hospeda-se na casa do tio, Serapião Ribas, um ricaço que habitava um palacete. $\mathrm{O}$ tio oferece ao sobrinho todas as comodidades e regalias. Anselmo conhece o Dr. Gomes, um guia inteligente que se propõe a mostrar-lhe a cidade e a "lhe explicar a psicologia humana" (BROCA, 1981, p. 185). O ápice da experiência urbana ocorre com a chegada de Anselmo à rua do Ouvidor. A urbanidade experimentada pela personagem é uma experiência da desilusão. E a primeira desilusão é logo a rua do Ouvidor.

Meu tio voltou-se com a bengala a fundo, risonho, mostrando-me uma rua em frente (...). Por atafulhou com o maço no bolso e, vagarosamente, desdobrou diante dos meus olhos uma folha de papel azul e, indicando-me uma frase com o dedo grosso, sorriu mirando-me. Era uma carta minha e o que ali estava debaixo do pesado e úmido indicador era apenas isto - "ver a rua do Ouvidor". Sem ler, mais estremecendo, cravei os olhos na rua... E sem uma palavra, mudo, abatido, como se me tivessem dado uma notícia de morte, suspirei.

- Uma surpresa, hein?

- Uma desilusão, meu tio, disse eu, murcho. (COELHO NETO, 1929, p. 64-65)

A desilusão ocorre porque, segundo palavras do próprio Anselmo nas páginas subsequentes, ele esperava uma rua suntuosa, ele a sonhara "com grandes casas apalaçadas, ruas cuidadosamente calçadas de mármore... arquitetura e gosto, arte e elegância, e largueza, sobretudo" (COELHO NETO, 1929, p. 65). E esbarra com a estreiteza da rua, "um beco". O sentimento que o oprimia era a morte de sua ilusão, e Anselmo mostrava a sua indignação contra aqueles que contribuíram para tamanha fantasia acerca da avenida do espírito fluminense.

Contaram-me tantas maravilhas desta rua que não é muito que me confesse desiludido, porque o sentimento que, em verdade, subjugo é de indignação contras todos quantos me atordoaram o espírito com exageradas fantasias e soberbas descrições de um fastígio incomparável. (...) Mentiram todos: a lei, a religião e a batota. Isto é uma miséria (p. 69). 
A importância desta pequena viela para a vida carioca é explicada ao Anselmo pelo seu tio, uma vez que somente um morador da cidade poderia entender o valor da decantada rua, "naquela época uma espécie de eixo em torno do qual girava Brasil" (BROCA, 1981, p. 185). Serapião considera a rua do Ouvidor uma "pia lustral que consagra os fatos e os homens" (COELHO NETTO, 1929, p. 71).

A meu ver a nossa forma de governo é a rua do Ouvidor; a nossa religião é a rua do Ouvidor - as constituições, os figurinos e os atos de fé saem deste beco (...) Esta rua ecoa todos os sucessos do mundo como na vida fisiológica o cérebro, por um fenômeno de repercussão nervosa, reflete todas as sensações do corpo (p. 71).

Com o desenrolar da história, Anselmo vai conhecendo e vivendo melhor a rua do Ouvidor. O seu "cicerone", Dr. Gomes, se encarrega de tão importante missão. E à decepção de ver uma rua do Ouvidor diferente de suas miragens, se sucedem muitas outras decepções decorrentes dessa experiência vivida de forma tão intensa por esse rapaz recém-chegado à Capital. "A vida noturna, os cassinos, a orgia, a alta sociedade, o amor; e o provinciano, depois de tais experiências, a qual não faltou uma tremenda carraspana, decide-se, apesar da insistência do tio, a voltar para a paz bucólica do seu recanto na roça" (BROCA, 1981, p. 185).

Pode-se perceber que a experiência decorrente da vida citadina se dá de forma oposta em A capital federal e A conquista. No primeiro, o regresso ao campo é a resposta às desilusões encontradas na cidade. A roça é o refúgio, uma resposta aos desenganos experimentados pela personagem. Anselmo se lembra das palavras de seu pai e se convence a ficar no campo.

Que trazia eu que demonstrasse ter vivido nessa cidade de luxo e de vicio, tão celebrada entre serras pelos que, uma vez, pisaram nas suas ruas e admiraram o seu fausto? Que trazia eu como documentos afirmativos? A carta de meu tio...? Sim, era uma verdade a carta, tanto que arrancara a meu pai estas profundas palavras cheias de sabedoria:

"Que me deixasse de sonhos. Que me dedicasse á terra, que é fonte perene de riqueza, porque neste país a lavoura é que rende, e citou a frase do estadista 'isto é um país essencialmente agrícola' aconselhando-me que não a perdesse de memória. Tudo mais, vaidade das vaidades." E ajuntou: "que mais valia ter uma junta de bois e uma charrua para sulcar o solo do que todas as cartas das congregações. E por fim, lembrou que aterra não produz perfídias nem calúnias e que viver entre as árvores é 
bem melhor do que viver entre os homens." Convenci-me e decidir ficar no campo, lavrando (COELHO NETO, 1929, p. 267- 268).

Já em A conquista, os boêmios, personagens do romance, são frutos da modernidade, são cidadãos urbanos. De acordo com Mendes (2008), em várias cenas, o "descanso" no campo é cansativo e entediante. Abandona-se, deste modo, o mito romântico da natureza como a panacéia universal. Anselmo, após uma estadia no campo, se mostra entediado com a "vidinha lânguida" de lá (COELHO NETO, 1985, p. 144).

- Não posso com isto, Pedroso. Estou ficando neurastênico. Há ocasiões em que tenho vontade de chorar.

- Por quê?

- Sei lá, à toa. É este silêncio, é esta monotonia, é tudo isto que me enfeza, que me irrita. (...) Vou para não morrer de tédio. Não posso ficar aqui a olhar milhos que amadurecem e galinhas que chocam (p. 144).

Em outro trecho do romance, Bivar (Olavo Bilac), o mais "parisiense" dos boêmios, declara sua preferência pela cidade. Sem a menor dúvida, o poeta trocaria a natureza por Paris:

- Nada como a cidade! Paisagens, só pintadas e por artistas de gênio. Não suportava um dia inteiro de écloga, à sombra de árvores, ouvindo cigarras, enxotando mosquitos e sempre arriscado a ser mordido de cobra. Isso de viver sub tegmine fagi era muito bom em literatura, na realidade preferia um bom hotel em Paris (p. 179).

Coelho Neto exprime de forma magistral nos dois romances a sensação do luxo e de civilização, associada à cidade. Em A capital federal temos o luxo em contraposição à vida simples de Anselmo. As análises do gozo e da opulência, a delicadeza do jantar, o exotismo do jardim - tudo passa diante dos olhos da personagem como um verdadeiro "orgasmo" estético. A beleza do lugar e o prazer da personagem são descritos em linguagem rica, com adjetivos brilhando por longas páginas. A ação fica suspensa, e há o ápice do processo descritivo em detrimento da narratividade.

Oh meu tio!

Exclamação quase infantil escapou-me dos lábios quando penetrei o santuário da limpeza. Que asseio e que fausto. (...) A sala vasta é toda de mosaico miúdo, talhado em triângulos brancos e vermelhos (...). Ao centro um espelho nítido de cristal, alto e grosso, onde se pode admirar a 
nudez das formas. (...) Aclamava esse interior de goze um lustre de seis globos cor de rosa (COELHO NETO, 1929, p. 29-31).

Já em A conquista, a escassez da vida boêmia é sempre posta em cheque a elementos luxuosos. Os salões, os teatros, os cafés, os restaurantes, são os locais de paradoxo entre o que se vive e o que se tem. $\mathrm{O}$ boêmio experimentava uma existência burguesa ao frequentar esses locais, mas voltava à miséria ao regressar para casa. A qualidade da moradia dos boêmios dependia da renda que podiam tirar da literatura. Eles passavam a juventude no Rio de Janeiro entre cortiços e casas de cômodos, sem muitas vezes ter o que comer. A fome é, assim, um tema recorrente na narrativa, responsável por doses de humor, uma vez que ela iguala o escritor aos simples mortais, retirando a áurea romântica que os revestia. Para escrever eles precisavam estar saciados: "Anselmo estava in albis e, como pretendia passar a noite trabalhando, porque tencionava dar começo a um romance (...) deteve-se na esquina da rua Uruguaiana farejando um jantar. Mas os jantares não passeiam na rua do Ouvidor" (p. 198).

Em outro trecho do romance Anselmo encontra Rui Vaz em um restaurante barato no centro da cidade. E estranhando a presença de seu amigo em semelhante estabelecimento, o indaga e recebe a seguinte resposta:

(...) Se o público soubesse quanto custa ser naturalista pagava os meus romances a preço de ouro. Vou às estalagens apanhar em flagrante a grande vida de tais colméias e, para que a gente não se perturbe com a minha presença, visto-me como carregador, meto-me em tamancos, subo às pedreiras, penetro, com risco de vida, as reles tavolagens, passo horas e horas entre a gente tremenda dos trapiches, converso com catraieiros e, finalmente, venho comer nessa baiúca, como vês.

- Mas, então, não foi por fome?

- Qual fome! Eu podia ter ido almoçar ao Globo, mas ando acompanhando um tipo.

- E onde está ele?

- Comeu e saiu. Para que não desconfiasse, porque ele já deve ter notado que o sigo, pedi um almoço e pus-me a comer... maquinalmente.

- Quiseste também fazer um estudo do bife que aqui se dá?

- Homem, não estás muito longe da verdade (...) (p. 245). 
Por trás da ironia presente neste trecho encontra-se uma verdade acerca destes escritores: estes homens das letras realmente eram presenças assíduas em estalagens e restaurantes frequentados por seus personagens, mas não o faziam somente por dever de profissão e sim pelo desprestígio desta e consequente falta de dinheiro.

Não se pode separar a existência boêmia de Coelho Netto do processo de construção destas narrativas. Ainda que ao escrever ele já tivesse abandonado a existência boêmia, ${ }^{3}$ ela engendra a construção romanesca. No romance $A$ conquista a experiência boêmia pode ser vista claramente. A saga da boemia é descrita na narrativa. O dobrar aleatório de esquinas que constrói o romance simboliza as andanças boêmias, a errância do grupo pela cidade. Em A capital fede$\mathrm{ral}$, a urbanidade não é visível na obra, mas é sentida. A prosa rica esbarra na simplicidade boêmia, se sobrepondo a escassez de recursos materiais. Desta forma, podemos dizer que se tem uma experiência urbana extradiegética, que vai para além do texto, que informa a modernidade já presente, apesar de negada, nestes romances.

Os romances $A$ capital federal e $A$ conquista apresentam no cerne de sua composição literária o gérmen da modernidade, esta não reconhecida pela crítica canônica, por motivos que aqui não cabem discutir. Segundo Barbosa (1990), a partir da segunda metade do século XIX, instala-se a noção de moderno, que, ao poucos, passa à categoria de avaliação literária. Porém, segundo ainda segundo o autor, é preciso não perder de vista o fato de que noção de moderno na literatura, articulada inicialmente à problematização de valores românticos, passa a servir para caracterizar textos e/ou autores que deixam entrever alguns elementos caracterizadores da composição literária moderna.

Esses romances apresentam modos de narrar que rompem com o ponto de vista privilegiado da narrativa e com o enredo progressista, típicos da narrativa realista do século XIX. "Alusões, paródias, humor, ironia, tudo serve para o escritor empenhado em inscrever o seu texto nos domínios de uma história contaminada pela consciência das desarticulações entre representação e realidade" (BARBOSA, 1990, p. 23).

${ }^{3}$ Ao confeccionar estes romances, Coelho Netto já estava casado - casou-se em 24 de Julho de 1890 - e por este motivo abandonara a existência boêmia. 
Essas duas narrativas, ainda, abrem mão do ato de narrar. Em A capital federal, a narrativa se constrói por meio do quase monólogo do Dr. Gomes, que é, desse modo, a personificação do abandono da narratividade. A ação romanesca fica suspensa e o romance se constrói no abandono da narratividade. Já em A conquista a ação romanesca se constrói por meio de encontros aleatórios no espaço urbano. A teia da narratividade também é quebrada com a construção de uma história que não se preocupa com uma estrutura romanesca linear.

Coelho Netto instaura "a linguagem das rupturas e suturas inesperadas onde tudo é válido porque tudo marcha para o aprofundamento das relações precárias, mas fundamentais, entre realidade e representação" (BARBOSA, 1990, p. 30). Ainda de acordo com Barbosa, o Moderno é o indissociável da insegurança: entre buscas, rupturas e retomada, o seu desígnio é a desconfiança em relação ao ajuste entre representação e realidade.

O abandono da narratividade, a ironia, os espaços e as configurações narrativas que experimentam a descentralização - tais como: a casa de cômodos, a zona portuária das cidades, as redações dos jornais, os cafés, os botecos - seriam maneiras de expressar a desconfiança do homem moderno em sua capacidade de apreender um mundo fragmentado. $\mathrm{O}$ escritor não consegue situar-se com clareza.

A experiência de vida boêmia de Coelho Neto é perceptível na jornada antiépica de Anselmo, e pode ser verificada nos dois romances. Em A conquista, Anselmo vaga por toda a narrativa. Aparecem neste romance as andanças aleatórias da boemia. O livro conta a história da geração privilegiada a que Coelho Netto pertenceu. Já em A capital federal, Anselmo experimenta a desilusão decorrente do empreendimento urbano. A saga da personagem submetida ao império do Acaso, o que pode sugerir as experiências de não pertencimento à estrutura social vigente e a existência liminar que Coelho Neto teria conhecido na juventude (OLIVEIRA, 2008).

O enredo banal, a narrativa sobre o nada, o monólogo narrado, o humor e a ironia impressos em algumas partes destes textos demonstram a problematização da capacidade em representar fielmente a realidade. Trata-se de uma espécie de ficção "sobre o nada" "que só seria realmente compreendida e apreciada no modernismo" 
(MENDES \& VIEIRA, 2009, p. 80). Neste espaço de articulação realidade/representação textual aparece a rua do Ouvidor, o local privilegiado de ficcionalização da experiência urbana, que reverbera nos dois romances como um todo.

Coelho Neto já apresenta sinais do moderno na construção dos romances estudados, visto que, segundo Barbosa (1990), o autor ou texto moderno é aquele que leva para o princípio de composição, e não apenas de expressão, um descompasso entre a realidade e sua representação, exigindo, assim, reformulação e rupturas dos modelos "realistas". Neste sentido, o que se põe em xeque é não a realidade como matéria da literatura, mas a maneira de articulá-la no espaço/ tempo do texto.

\section{REFERÊNCIAS BIBLIOGRÁFICAS}

ASSIS, Machado de. Tempos de crise. In: Outros contos. Obra completa. Vol. II, Rio de Janeiro: Nova Aguilar, 1994. Publicado originalmente em Jornal das Famílias, abril de 1873.

BARBOSA, João Alexandre. A modernidade no romance. In: . A leitura do intervalo. São Paulo: Iluminuras, 1990.

BROCA, Brito. Ensaios da mão canhestra: Cervantes, Goethe, Dostoievski, Alencar, Coelho Netto, Pompeia. São Paulo: Polis; Brasília: INL, 1981, 11 v. (Coleção estética: série obras reunidas de Brito Broca).

BROCA, Brito. A vida literária no Brasil - 1900. Rio de Janeiro: Imprensa Nacional, 1956.

COELHO NETTO, Henrique. A capital federal. Porto: Lello, 1929.

COELHO NETTO, Henrique. A conquista. Rio de Janeiro: Civilização Brasileira, 1985.

LEITE, Ligia Chiappini Moraes. O foco narrativo (ou a polêmica em torno da ilusão). São Paulo: Ática, 1985. Série Princípios.

MENDES, Leonardo \& VIEIRA, Renata Ferreira. A república manca: Miragem, de Coelho Neto e o naturalismo da desilusão. Soletras, Ano IX, No 18. São Gonçalo: UERJ, 2009. 
MÉRIAN, Jean - Yves. Aluisio Azevedo e a boemia literária. In: . Aluísio Azevedo, vida e obra: (1985-1913). Rio de Janeiro: Espaço e tempo banco Sudameris - Brasil; Brasília: INL, 1988.

OLIVEIRA, Diogo de Castro. Onosarquistas e patafísicos: a boemia literária no Rio de Janeiro fin-de-siècle. Rio de Janeiro: 7Letras, 2008.

RIO, João do. A alma encantadora das ruas. Organização de Raul Antelo. São Paulo: Companhia das Letras, 1997.

RODRIGUES, Nilton Júnior. Vidraças do Ouvidor: a rua do Ouvidor na formação do capitalismo carioca. Revista Espaço Acadêmico - N o 65 - Outubro/2006. Ano VI. Disponível em:

http://www.espacoacademico.com.br/065/65rodrigues.htm. Acesso 07/07/2010.

TRIGO, Luciano. O viajante imóvel: Machado de Assis e o Rio de Janeiro de seu tempo. Rio de Janeiro: Record, 2001. 